\title{
Billion Plaque Forming Units
}

National Cancer Institute

\section{Source}

National Cancer Institute. Billion Plaque Forming Units. NCI Thesaurus. Code C67267.

A measure of viable infectious entities expressed in billions in the specimen or product defined as the smallest quantity that can produce a cytopathic effect in the host cell culture challenged with the defined inoculum, visible under the microscope or/and to the naked eye as a plaque. 